\title{
Pursuing Sustainability in the Euro-Mediterranean Area: The Role of Agricultural Finance
}

\author{
By Margherita Mori*
}

This paper deals with sustainability issues that call for unprecedented attention in the financial industry, as well as in other market segments. Focusing on how it can support agriculture and food systems in the Euro-Mediterranean area may prove rewarding; lessons learned are likely to turn useful elsewhere, due to widely shared challenges. The agribusiness has been confronted with unexpected difficulties since 2007, such as agflation and its socio-economic effects, the subprime crisis, and environmental degradation. Meanwhile deep-rooted problems have mostly remained unsolved: many farms are still undersized; land is seldom used efficiently, and firms tend to be owned and operated by families; as such, managerial criteria do not fully display their potential and the flight to quality depends on the role of finance to a significant extent.To make it more and more appealing, the financial sphere of the economy looks like a huge laboratory with both physical and virtual features. Sorting out the most fruitful advancements and replicating them will help to promote sustainable finance, to the benefit not only of local markets, due to increasing globalization: upgrading the supply of financial services to rural areas is a vital part of addressing issues that pervade our globalized economy, such as those pertaining to food security and poverty reduction, thus contributing to sustainable development. All in all, expansion of agricultural finance can generate a win-win situation that may foster growth even where financial inclusion is by itself a challenging task. Furthermore, positive synergies can be exploited by promoting clusters, such as industrial and technological districts that specialize in agricultural commodities and that may take advantage of economies of scale while getting access to finance. Building capacity, pursuing innovation and enriching knowledge sound like promising goals in the area under investigation, as well as in our global village as a whole.

Keywords: Agribusiness, Agricultural finance, Financial innovation, Rural finance, Sustainable development.

\section{Introduction}

Nobody would deny that the agricultural sector can still contribute to a significant extent to the growth of our global village, to the benefit of present and future generations; such a relevant contribution becomes even more evident when the notion of growth is better defined, so as to highlight sustainability issues. Supporting arguments stem from - among others projects that refer to this sector and that have been developed in sight of relying on biological processes, recycling as much as possible, and expending minimal amounts of energy.

\footnotetext{
${ }^{*}$ Professor, University of L'Aquila, Italy.
} 
In turn, finance is crucial to the growth of this sector, as it can be argued by analyzing recent trends towards improving financial inclusion of smallholders farmers. Yet, much more attention should be paid to agricultural finance, that looks like an emerging market segment in the financial industry which by the way also faces sustainability issues: a case in point has to do with the adoption of responsible lending principles, that imply - but are not limited to - the promotion of inclusive finance and prevention of overindebtedness; they also entail responsible decisions by financial institutions, which are expected to emphasize the environmental and social impacts of their investment and particularly of their loans.

The link between agricultural finance and sustainable development warrants special interest in the Euro-Mediterranean area, thus requesting to widen the scope of studies that refer to "the most economically disadvantaged developing countries" (DID 2010: 1): be it enough to stress that investing in resilient agriculture and rural livelihoods may help European countries to cope with migration policy issues and people on the other shore of the Mediterranean Sea to stay on their land, as suggested by Food and Agriculture Organization of the United Nations (FAO 2016). In the light of these challenges, the main objective of this study is to discuss how agricultural finance can be better resorted to, in an attempt at exploiting its potential contribution to sustainable growth in this area, and to reach conclusions based on key messages and recommendations for policy interventions, as well as for further research and development.

\section{Literature Review}

\section{Sustainability Issues}

Cross-cultural issues that pertain to sustainability have continued to grow in popularity since the adoption of a wider perspective than the original one, centered upon natural resources, their protection, conservation and quality. The overall picture is pervaded by the efforts undertaken in order to make knowledge progressing on topics that are closely related to sustainable development; yet, there is no universally agreed meaning of the word sustainability and many different opinions have been expressed on how this concept can be put into practice.

Anyway, the pursuit of a sustainable future stands as a widely shared goal, which leads to stress the combination of sustain and ability. Basic definitions can be traced back to the Earth Summit that took place in Rio de Janeiro, Brazil, on June 3-14, 1992 and that remains unprecedented for a conference arranged by the United Nations (UN) in terms of scope of its concerns: this event marked the adoption of several agreements aimed at changing the traditional approach to development, including a comprehensive program for global action in all areas of sustainable development; it was intended as representing an alternative approach to simply pursuing economic growth. 
What made - and still makes - a true difference is the willingness to meet "the needs of the present without compromising the ability of future generations to meet their own needs", according to the World Commission on Environment and Development (WCED 1987). As such, sustainable development is described as being based upon the concept of "needs" and overriding priority is claimed on behalf of the world's poor: not only large sections of the population cannot satisfy their basic needs for food, clothing, shelter and jobs, but it also seems legitimate for people to have aspirations for an improved quality of life, beyond meeting their basic needs; in other words, achieving full growth potential does not tell the whole story, according to most often quoted references, and ill-considered development tends to be depicted as a potential source of even greater problems.

\section{"New Agriculture" and Sustainable Development}

There it follows that - at least - sustainable development should not endanger the natural systems that support life on earth and efforts have been evoked in sight of preserving the environment's ability to meet present and future needs. Focusing on the agricultural sector, it has been reportedly reshaped by globalization, standardization, high-value production, massive growth in demand, retail and packaging innovations: the "new agriculture" is "faced with constant productivity and market pressures" (Gálvez-Nogales 2010: x); meanwhile, international organizations are committed more than ever to ethical and global goals, including the aim of sharing knowledge on the topics under investigation.

$\mathrm{Be}$ it enough to mention the International Bank for Reconstruction and Development (i.e. the original World Bank institution) and the International Fund for Agricultural Development (IFAD), besides FAO with its Investment Centre: no surprise, provided that "agricultural growth remains central to poverty reduction, particularly in the poorest countries, where a large share of the population relies on agriculture for their livelihood" (World Bank 2011: ix). To add the sustainability dimension, "agriculture and its many associated value addition agribusinesses and services must play a crucial role in order to meet the 17 new global Sustainable Development Goals (SDGs), including their important goals and targets toward ending hunger, poverty and reducing inequality by 2030" (GPFI 2015: 7).

Therefore, by common opinion, enhanced agricultural growth can be considered a must, not just an option, and the growth to be pursued should qualify as sustainable, as implied by the increasing energies that have been devoted in the last few years to foster a bio-based economy in Europe (EC 2011). To this end, useful insights are provided by the "Europe 2020" agenda that should enable each Member State in the European Union (EU) to become a sustainable - as well as an inclusive and a smart - economy: it is spelled out that sustainable growth depends on a "more resource efficient, greener and more competitive economy"; a smart growth is based on "knowledge and 
education"; and an inclusive growth implies "a high employment economy delivering social and territorial cohesion" (EC 2010: 8).

\section{Financial Implications}

As far as the role that can be played by the financial sphere of the economy, an interesting debate has been developed in sight of pursuing higher and higher sustainability levels, as well as by searching for ways to boost agricultural finance. On one hand, sustainable finance has received increasing consideration, especially in an attempt at promoting responsible lending in the field of project finance, which should encompass social, environmental and governance standards (CSAF 2016); it is not a case that more than seven years after the beginning of the global financial crisis, the EC announced a Capital Market Union refresh "including the establishment of an expert group to develop a comprehensive strategy for sustainable finance" (Holmes and Maule 2016: 4).

On the other hand, both academics and practitioners have recently intensified their endeavors to figure out how to deploy investment to address the demand for specific financial services in agriculture and related market segments and particularly to satisfy the needs of smallholder farmers (Carroll et al. 2012) according to several studies and reliable statistical data, they occupy an important segment in the global agricultural value chain but remain financially excluded and vulnerable to a remarkable extent. It comes natural to stress that agricultural finance empowers poor farmers to increase their wealth and food production to be able to feed 9 billion people by 2050 (World Bank 2015).

For such ambitious goals to be reached, innovative models are requested in financing farmers, as well as in managing agribusiness and related market segments. A survey of possible ways to improve the balance between demand and supply leads to consider the opportunity to combine financial and nonfinancial services dedicated to farmers and to downscale to smallholders approaches that have worked for larger farmers (IFC 2012); forward steps have also been envisaged by promoting vertical and horizontal links between local agricultural enterprises and by inducing agro-based clusters that concentrate producers, agribusinesses and institutions in the same agricultural or agroindustrial subsector, even in developing countries.

\section{The Euro-Mediterranean Area}

Though most of these issues lend themselves to be defined global without hesitation, available literature leads to also take into careful account the peculiarities surfacing in local markets and - in more general terms - to adopt criteria inspired by geographical segmentation. Useful insights can be gained by focusing on the Euro-Mediterranean area: in a broad sense, it can be assumed to include the 43 countries that belong to the Union for the Mediterranean, an intergovernmental institution bringing together the EU 
Member States and several countries from the Southern and Eastern shores of the Mediterranean; they are Albania, Algeria, Arab League, Bosnia and Herzegovina, Egypt, Israel, Jordan, Lebanon, Mauritania, Monaco, Montenegro, Morocco, Palestine, Syria (self-suspended since December 1, 2011), Tunisia and Turkey, with Libya having an observer status.

Referring to this area as Euro-Mediterranean may suggest divergent opinions: it includes EU countries that do not border the Mediterranean Sea, since their exclusion would imply an artificial distinction between Northern and Southern Europe; in addition, the proposed area puts together countries that belong to both Africa and the Middle-East. Yet, shared problems - and joint efforts that may be undertaken in an attempt at solving them - grant a certain unity to the area at issue and this unitary vision allows to minimize the ambiguities stressed by Copoeru, et al. (2011: 7), upon defining "the naming of the vast area called 'Euro-Mediterranean' ... ultimately inadequate".

By contrast, there are authors that privilege the set of countries in the Middle East and North Africa (known as MENA), as shown by Paciello (2015) they cover an extensive region that has no standardized definition; according to the World Bank ${ }^{1}$, this area includes Algeria, Bahrein, Djibouti, Egypt, Iran, Israel, Iraq, Jourdan, Kuwait, Lebanon, Libya, Morocco, Oman, Qatar, Saudi Arabia, Syria, Tunisia, United Arab Emirates, West Bank and Gaza, and Yemen. In order to account for European countries too, it should be better consider the EMEA region, that is generally accepted to encompass all European and African nations and extends east to Iran and Russia, while independent territories of mainland countries in the region itself are typically excluded (such as French Guyana).

\section{Methodology}

To sum up, a review of the literature reveals that a quite intensive debate has been developed since the end of the last century on sustainability issues, whereas agricultural finance has not attracted yet as much attention as it deserves. An evident gap involves the relationship between sustainable development and agricultural finance, with a special emphasis to be put on the Euro-Mediterranean area, and it is not just a matter of methodology: a quest for relevance can be easily perceived in different disciplines, that are linked to financial management but are not strictly limited to it; scarcity of resources and mismanagement in agribusiness and related segments give ground for developing ideas that can offer useful insights and practical tools, as well as for exploring future scenarios, which entails an effort that will surely pay off.

Such a challenging link is the focus of this conceptual and explorative study, that is carried out in sight of addressing the most pressing questions, is motivated by the need for a framework for analysis and decision making, and refers to the Union for the Euro-Mediterranean. Within this area, a case-study

\footnotetext{
${ }^{1}$ See http://www.worldbank.org/en/region/mena. Accessed 2 July, 2017.
} 
approach seems appropriate, in order to discuss how to promote sustainable development, based on the potential of agriculture and food systems, and to emphasize the role that can be played by the financial sphere of the economy; special consideration is paid to agricultural finance, despite - or thanks to being its conceptualization still relatively recent, which leads to stress its most favorable implications.

Actually, the financial arena can be regarded as a huge laboratory with both physical and virtual features: sorting out the most fruitful advancements and replicating them would certainly prove rewarding, in sight of pursuing sustainability in the Euro-Mediterranean agribusiness and related segments; contributing to a purposeful dialogue with practitioners and the business community may prove beneficial to society at large. Success stories have been - and can still be - identified that encourage to proceed, as it can be said of pre- and post-harvest financing promoted and supported by the European Bank for Reconstruction and Development by means of crop receipts and warehouse receipts in several countries, not only in Europe ${ }^{2}$.

\section{Findings}

\section{The State of the Art}

There can be no question that sustainability issues call for unprecedented attention in agriculture and food systems, as well as in other market segments, including the financial system. This is especially true in the EuroMediterranean area, where unexpected difficulties have surfaced since 2007 the consequences of a sharp rise in agricultural commodity prices at that time were felt right down the menu and evolved into economic, social and political problems, while the financial crisis that originated from US subprime mortgage loans started to severely affect the real sphere of the economy and did not spare the agribusiness; at the same time it has been impacted by environmental degradation and its side-effects, such as climate change, water stress and periodic droughts, which fueled the debate on sustainable development in sight of fulfilling the so-called "generation pact".

As if these problems were not enough, deep-rooted undesirable features still pervade the area under investigation and continue to undermine the competitiveness of its agriculture and food systems: to give just a few examples, many enterprises are undersized and, as such, not viable; land is not used efficiently, with very few exceptions; most of the firms are owned and operated by families. No wonder that managerial criteria do not fully display their potential and that much room remains to upgrade the level of financial skills, in combination with a wider and deeper supply of dedicated financial services in the chosen field of analysis.

\footnotetext{
${ }^{2}$ See http://bit.ly/2sFKIYv. Accessed 27 June 2017.
} 
In order to move forward steps, it seems convenient to rely on financial innovation, that has allowed new financial products, institutions and market segments to proliferate for decades and that looks far from exhausted. The concept of agricultural finance itself is still recent and focusing on its implications may help to promote sustainability in the Euro-Mediterranean area, given the crucial role of the agribusiness: lessons learned in this area, as elsewhere, may prove useful even to better bridge the gap between theory and practice, as shown by the wider recourse to blended finance, whereby "public and/or philanthropic inputs 'leverage' or catalyse a private investment that otherwise would not be made, creating positive development outcomes" (Lonsdale 2016: 4); benefits to agriculture and food systems are likely to spread to related industries, that make up a very long list, including tourism and particularly rural tourism, ecotourism and responsible tourism (Mori 2008) - to disclose probably the most surprising and attractive link.

\section{Presentation of Case}

The heterogeneous features of the countries that belong to the area under investigation give ground for discussing peculiar strengths and weaknesses. To begin with, Southern Mediterranean countries have been confronted with challenges that mostly stem from the region's heavy reliance on food imports: not surprisingly, efforts continue to be made - for example - in order to fulfill the objective of inclusive rural transformation; it is expected "to generate improved and more stable livelihoods for all rural people, including small-scale farmers, land-poor and landless workers, women and youth, marginalized ethnic groups and victims of disaster and conflict" (IFAD 2016: 162).

Anyway, the agribusiness has been - and still is - under pressure elsewhere in the area under investigation: the sharp increase in the cost of agricultural commodities in 2007 evolved into agflation - a combination of "agriculture" and "inflation" - at the same time as the global financial crisis started to severely affect the real sphere of the economy; meanwhile, high and volatile food prices have brought about negative consequences in terms of macro-economic problems (inflation, trade deficits, and fiscal pressure, to mention just a few of them), as well as increased poverty and political instability. Further challenging issues have to do with environmental degradation and its repercussions, such as climate change, water stress and periodic droughts, which leads to consider sustainable development in agriculture and food systems of particular concern in the Euro-Mediterranean area.

Looking at the EU, not only this market segment has been impacted by the 2007-2008 world food price crisis and by the subprime crisis, but it also has to be accounted for the interdependence of Southern Mediterranean and European economies. Needless to say, these challenges should be better met by undertaking joint action towards a more sustainable scenario, which requires a strong commitment to pursue "the" equilibrium between cooperation and competition, in sight of improving the well-being of present and future 
generations through the promotion of sustainable development: the "generation pact" stands as a vital part of generational sustainability which adds a new dimension to sustainable development and allows the youth element to contribute as a strategic asset to the evolutionary processes under way all over the world.

\section{Finance as a Key Ingredient}

Within this conceptual framework, it can be taken for granted that joint efforts are needed in order to solve shared problems, such as those pertaining to food security (Benabderrazik 2012), though this need remains largely unsatisfied in the area at issue as a whole, partly due to fears that competition from the Southern Mediterranean may have a negative impact on the European agribusiness; actually, "enhanced competitiveness of the EU agriculture" is one of the pillars that 2013 reform of CAP (Common Agricultural Policy) has been based on (EC 2013: 7). The ban imposed by Russia on most imports of Western food products in retaliation for the West's own sanctions over the Ukraine crisis has further deteriorated the picture since 2014, thus contributing to hinder the economic growth in Europe.

Inadequate cooperation also interferes with the search for adequate solutions to deep-rooted problems. The shortage of managerial skills, the need for innovation (including new, tailor-made financial services), the small size of the enterprises prevailing in agriculture, the inefficient use of land with very few exceptions are the most often quoted - but not the only - undesirable features that continue to prevent the flight to quality in the agribusiness, in Europe too, where most of the farms are still owned and operated by families; these are the main reasons why managerial criteria do not fully display their potential in agriculture.

Based upon these considerations, it is worth the effort of assessing strategies that may be adopted for the agribusiness to contribute to sustainable development on both shores of the Mediterranean, from which many market segments can be expected to benefit; their list is almost endless, including not only agriculture but also agrochemicals, breeding and crop production, farming and farm machinery, food production and processing, seed and water supply, forestry and forest management, marketing and retail sales, rural and ecotourism, food quality and safety, to mention just a few, most relevant segments. In order to progress within this framework, much depends on improving financial skills, provided that money is an essential input as well as a scarce resource.

\section{A Closer Look at Financial Innovation}

Focusing on financial innovation, it must be recognized that this process is likely to spur sustainable finance which in turn should help to upgrade the way in which the agribusiness is currently managed. Actually, scholars and practitioners have tried to cope with emerging issues in managerial finance for 
decades, thus generating a remarkable quantity of high quality information; however, forward steps can be still taken in order to promote a more massive recourse to financial management in agriculture and food systems, as argued by Ushie (2013).

Taking advantage of the process of financial innovation may help to spur a long-term, sustainable growth in the agribusiness - just like in other economic sectors - which by the way does not mean that traditional financial services are no longer useful. In order to progress along this pathway, the starting point can be identified with a critical overview of the empirical research and theoretical models developed in the field of financial innovation; a survey of new financial services, market segments and institutions may prove useful but it must be taken for granted that changes occur on a daily basis because financial innovation is an ongoing process, far from being exhausted.

The next step has to do with sorting out the strategic tools that are suited the best to satisfy the financial needs pervading the agribusiness and especially its multitude of small enterprises, not to mention the micro ones: in a few words, it is a matter of continuously monitoring the financial arena and realizing what is new that may prove beneficial to agriculture and food systems, with the local perspective to be properly combined with the global one, according to the glocal approach; for the best results to be achieved, a cross-cultural perspective is also advisable, as implied by the argument that sustainable finance and sustainable agriculture are likely to go hand in hand. A case in point as to do with the trend towards promoting local agricultural products and food, which makes building sustainable agriculture for food security a particularly challenging task, not only in the Euro-Mediterranean area.

\section{Discussion}

New Strategic Tools

While searching for the most promising ways to succeed, the widely shared need to enhance economies of scale is just one of the challenges to be met in sight of promoting sustainable development - in agribusiness, as well as in the financial system and in other market segments - and policy options should be dealt with by assuming a broad perspective, including new ways of delivering financial services. A good example is represented by the mobile classroom that the Louisiana Business \& Technology Center (Baton Rouge, LA, USA) has made recourse to since 2005, after Hurricane Katrina: this custom-designed 18-wheeler trailer allowed to provide managerial assistance to unserved parishes in rural Louisiana after Hurricane Katrina; such a strategic tool has been used to host seminars and workshops for small business owners and has displayed its usefulness well beyond the initial scope ${ }^{3}$.

\footnotetext{
${ }^{3}$ See http://bit.ly/2sp3kHR. Accessed 27 June 2017.
} 
In sight of these ambitious goals, valuable support may be provided also by a wider adoption of the best practices that the financial system can make available to the agribusiness, such as the Equator Principles and sustainability indexes which are designed to emphasize the environmental and social impacts of investing, and particularly of lending (Mori 2012). Further useful insights can be gained by considering the fact that public finance cannot help as much as needed, being under severe pressure; as a consequence, Public Private Partnerships (PPPs) should be promoted more and more heavily as an important institutional mechanism for gaining access to additional financial resources, sharing risks and better coping with constraints to the pursuit of sustainable agricultural development, as shown by Delmon (2010).

Despite the efforts undertaken by the European Commission for many years for PPPs to prove successful (EC0 2003), best practices and experiences on using them to initiate agricultural programs have not been widely disseminated so far. Outside Europe, various forms of collaboration between the public and private sector have existed for some time and valuable evidence about PPPs in agribusiness has been made available by a series of appraisals that have been carried out by FAO since 2010 in Africa, Asia and Latin America: success stories have been identified in several countries, including Pakistan, Indonesia, Thailand, Kenya, United Republic of Tanzania, Ghana, Nigeria (Slater, at al., 2016) and may provide precious guidance in the EuroMediterranean area; actually, these appraisals contribute to enriching knowledge and sharing information on the mechanisms of PPPs for informed decision making on investment promotion and hence for engendering progress in the agribusiness ${ }^{4}$.

\section{The Role of International Institutions}

If it is true - as it is - that international organizations can play a key role, special consideration should be devoted to how the potential for domestic food production and food security in Southern Mediterranean countries may be improved by the EU, due to its valuable experience not only with its CAP but also with initiatives such as JEREMIE (Joint European Resources for Micro to Medium Enterprises) and JASMINE (Joint Action to Support Micro-finance Institutions in Europe). To make a long story short, JEREMIE was announced in 2005 by the European Commission in cooperation with the European Investment Bank Group in order to make cohesion policy more efficient and sustainable: thanks to this project, EU Member States have been offered the opportunity to use part of their Structural Funds to support small and mediumsized enterprises in accessing finance by means of equity, loans and/or guarantees; the recourse to these and other financial engineering instruments "offers a more sustainable alternative to the assistance traditionally provided through grants" 5 .

\footnotetext{
${ }^{4}$ See http://bit.ly/2tPIR3r. Accessed 27 June 2017.

${ }^{5}$ See http://bit.ly/2tI2WIt. Accessed 2 July 2017.
} 
As far as JASMINE, it is a joint initiative of the European Commission, the European Investment Bank and European Investment Fund that has been under way for about 10 years: thanks to this project, activities in the field of microcredit have been developed within the framework of JEREMIE; goals have been designed to disseminate good practices in the EU with regard to microcredit lending. Up to now, much support has been offered to foster the development of microcredit providers in member countries and to help these intermediaries to become sustainable operators on commercial terms ${ }^{6}$, with a special emphasis to be put on risk management and strategy planning.

A closer look at the "Europe 2020" agenda too may prove beneficial as a source of ideas to be implemented in the Southern Mediterranean area in the light of promoting a smart, sustainable and inclusive growth, thanks to multiyear strategic partnerships, including PPPs. A special emphasis should be put on increasing finance and investment to rural areas, which can be considered a vital part of addressing food security and poverty reduction, due to the many factors that continue to interfere with the development of vibrant financial markets in most rural areas: a case-by-case analysis reveals an under-provision of financial services in these areas, where relatively high transaction costs are recorded as a result of dispersed populations, their small-scale needs, inadequate infrastructure and specific risk factors; an interesting example is the largely unsatisfied need for agricultural insurance designed to cover - or at least minimize - the risks of being impacted by adverse weather events (droughts, excessive rains, storms and hurricanes among them) that may cause huge losses to farmers.

\section{Focus on Rural Finance}

Turning to the demand side, it seems that the capacities of rural households and agricultural producers tend to be overlooked, thus unveiling financial inclusion as a crucial issue: the inability to access capital - or to borrow money at a competitive interest rate - may prevent them from taking advantage of market opportunities; the scarce availability of financial products designed to cover risks tend to discourage from undertaking profitable projects for which adequate liquidity is - by contrast - available. Competitive savings instruments too tend to underestimate the needs emerging from rural areas, thus cutting further into their scarce liquidity and further dampening local growth prospects.

Given the high proportion of poor populations that live in rural areas, the growing income inequality between urban and rural markets, the concerns for food security, the vulnerability of people belonging to rural communities, an increased attention needs to be paid to financial deepening of rural areas as part of a strategy to stimulate rural private sector development. New approaches, technologies and forms of investment may help to speed up improvement in rural financial services, that should also cover the field of savings mobilization

\footnotetext{
${ }^{6}$ See http://bit.ly/2sLHtKo. Accessed 27 June 2017.
} 
(Seibel and Kirchstein 2011): good examples are investments in the intensification in sustainable agriculture in addition to investments in sustainable natural resource management for agriculture.

Such challenging tasks require an intensive activity on research and development of agricultural investment funds, as well as on promotion of guarantee funds and information communication technology, in order to increase the level of investment while reducing the risks to investors in the agribusiness; financial education in this market segment may also prove rewarding as a way of reaching out to rural populations and accelerating rural finance (Athmer 2008), including relevant market segments, such as those pertaining to remittances, seed capital packages, crowdfunding, insurance policies, guarantees and technical assistance. Further developments may be promoted by taking advantage of still unexploited opportunities, such as those in the fields of e-banking and group lending within the framework of agricultural finance.

\section{The Potential for Progress}

In order to bridge the gap between theory and practice, it is useful to refer to FAO once again and define rural finance as encompassing the range of financial services supplied and used in rural areas by people of all income levels ${ }^{7}$. This broad definition reportedly includes agricultural finance, agricultural value chain finance and agricultural microfinance: agricultural finance is dedicated to financing agricultural related activities, such as input supply, production, distribution, wholesale, processing and marketing; agricultural value chain finance is based upon inter-linked processes from farms to consumers and tends to increase efficiency while reducing risk in lending; agricultural microfinance is aimed at the provision of financial services to poor and low income people by offering small-sized loans and savings services, and has good chances to prove more and more beneficial in the agribusiness, just like in other economic sectors (Mori 2011).

From this wide perspective, expansion of rural financial services is likely to create a win-win scenario thus helping to reduce poverty and promote sustainable growth even where financial inclusion is by itself a tough task, as shown by the remarkable development of the Moroccan microfinance sector (CGAP 2009). Positive results can also be attained by promoting tools that can support the "new" rurality on both shores of the Mediterranean and that include agribusiness incubators: the underlying entrepreneurial development model provides a common environment (either physical or virtual) to nascent agrobased companies that this way can get access to shared infrastructure, as well as to networking, coaching, business and financial services.

There can be no doubt that supporting entrepreneurship and innovation is important in Europe, as well as in the Southern Mediterranean area. Therefore, common solutions are highly desirable in order to tackle shared challenges,

\footnotetext{
${ }^{7}$ See http://bit.ly/21KxxlH. Accessed 27 June 2017.
} 
such as the ones pervading agriculture and food systems: an equilibrium should be pursued between cooperation and competition in spite of the fact that agriculture has been marginalized so far within the framework of the EuroMediterranean relations; in a few words, the global competitive challenge implies sustainability issues to be jointly faced and finance is a key ingredient that still needs to be exploited to a significant extent.

\section{Academic Challenges}

Actually, building capacity, pursuing innovation and enriching knowledge sound like promising goals that may contribute to competitive value chains, in line with the results of specific projects, in agribusiness as well as in other market segments (Alidou et al. 2010). Policies to be explored cannot bypass the need to focus on research, which local Universities are likely to significantly contribute to: it is undisputable that "agricultural universities and faculties of agriculture in universities face challenges of providing relevant and high quality training for future agricultural scientists, mobilizing funding for research, disseminating research findings, and recruiting, promoting and retaining gifted teachers and researchers" (World Bank 2005: 78); a network of most relevant partners and institutions in the region under scrutiny may help to jointly face difficulties and replicate ideas that has been successfully implemented elsewhere.

Areas that deserve more attention include education in rural finance, and particularly agricultural finance, as well as in blended finance: accelerating knowledge creation in this field, creating new insights and disseminating best practices that also refer to related market segments are tasks that cannot be underestimated, in order to upgrade the level of financial literacy of potential users of the relevant tools; in most cases, available financial instruments are not accessed to just because the relevant target market is not aware of their existence. As a consequence, it sounds reasonable to expect a valuable contribution from this improved awareness to sustainable growth in the EuroMediterranean area, as elsewhere.

Besides improving financial inclusion, Universities in this area can devote energies to develop scientific projects, as well as to activate and gather skills and resources, in an attempt at generating and disseminating operational models that may accelerate glocal progress, even in sight of addressing some of the root causes of migration in protracted crises and assisting displaced populations. A review of the literature reveals that available empirical analyses are relatively recent and in a limited number: gathering field evidence is just one of the activities beyond the reach of individual research workers, not to mention the need to facilitate closer linkages with practitioners and financial institutions at the international level, as well as between public and private investors: despite the growing interest shown by commercial investors in agribusiness, public incentives and support are required to compensate for their focus on financial returns (FAO 2015). 


\section{Conclusions}

To conclude, promoting sustainable development should be accompanied by an easier access to credit and financial services, which spearheads the priority list in agribusiness. Its evolution may benefit from the "Europe 2020" agenda and particularly from the efforts under way toward a smart, sustainable and inclusive growth; options to be adopted within the framework of EuroMediterranean cooperation may also draw upon EU initiatives that have been developed over the last decade, such as JEREMIE and JASMINE, since the underlying institutional mechanism represented by PPPs enables to better cope with the constraints to the pursuit of sustainable development.

Compelling evidence stems from a series of appraisals undertaken by FAO since 2010: they confirm that increasing finance and investment to rural areas is a vital part of addressing food security and poverty reduction; hence, the expansion of agricultural finance can generate a win-win situation that will foster growth even where financial inclusion is by itself a challenging task, as shown by the remarkable progress recorded in the Moroccan microfinance sector. Lessons learned worldwide also suggest new ways of supporting rural areas with financial assistance, which entails a comprehensive approach based upon the cooperation of all actors involved (banks and other financial intermediaries, insurance companies, microfinance institutions, micro-loan organizations and funds, micro-deposit organizations, as well as government agencies, non-governmental organizations, foundations and other private donors, with peer-to-per online lending platforms being set to increasingly satisfy specific needs).

Furthermore, positive synergies can be exploited by promoting clusters, such as industrial and technological districts that specialize in agricultural commodities: building capacity, pursuing innovation and enriching knowledge sound like promising goals that local Universities are likely to contribute to; a network of most relevant partners may help to jointly face difficulties and spread best practices, in line with the institutional role of academics. All in all, sharing pain is usually deemed a good thing but who would not rather share success stories?

\section{Acknowledgments}

The author would like to gratefully acknowledge the anonymous referees who reviewed this manuscript on behalf of Athens Institute for Education and Research (ATINER). Usual disclaimers apply. 


\section{References}

Alidou M, Lem M, Schrader T, de Zeuw F (2010) Local entrepreneurship, agribusiness cluster formation and the development of competitive value chains Evaluation of the Strategic Alliance for Agricultural Development in Africa (SAADA program) 2006-2009, (Sept. 2010). Berenschot, Wageningen UR, Wageningen, The Netherlands.

Athmer G (2008) Rural Finance Study. ICCO, Utrecht, The Netherlands.

Benabderrazik H (2012) Food Security South of the Mediterranean: How can the European Union contribute? In Transitions in North Africa in Times of Scarcity Finance, Employment, Energy \& Food - The Mediterranean in a multipolar World up to 2030 (Mar. 2012). CIDOB Foundation, Barcelona, Spain.

Carroll T, Stern A, Zook, D, Funes, R, Rastegar A, Lien Y (2012) Catalyzing Smallholder Agricultural Finance (Sept. 2012). Dalberg Global Development Advisors. Retrieved from http://bit.ly/10hFyyH. [Accessed 27 June 2017].

Consultative Group to Assist the Poor (CGAP), World Bank Group 2009. The Rise, Fall, and Recovery of the Microfinance Sector in Morocco (Dec. 2009). Washington DC, USA.

Council on Smallholder Agricultural Finance (CSAF) (2016) 2015 Year in Review: Increasing Impact \& Managing Risk. Retrieved from http://bit.ly/2toutvQ. [Accessed 27 June 2017].

Copoeru I, Kontos P, Serrano de Haro A (Eds) (2011) Phenomenology 2010. Vol. 3. Selected Essays from the Euro-Mediterranean. The Horizons of Freedom. Bucharest, Romania: Zeta Books,.

Delmon J (2010) Understanding Options for Public-Private Partnerships. In Infrastructure, Policy Research Working Paper n. 5173 (Jan. 2010). The World Bank, Finance Economics \& Urban Department, Finance and Guarantees Unit, Washington DC, USA.

Desjardins Développement International (DID) (2010) Agricultural Financing: A powerful tool for contributing to the food security of the populations - Position Paper (Nov. 2010). Lévis (Québec), Canada.

European Commission (EC) (2003) Guidelines for Successful Public-Private Partnerships. Brussels, Belgium.

European Commission (EC) (2010) Europe 2020 - A European strategy for smart, sustainable and inclusive growth (March 3, 2010).

European Commission (EC) (2011) Bio-based economy in Europe: state of play and future potential - Part 2. Brussels, Belgium.

European Commission (EC) (2013) Overview of CAP Reform 2014-2020 (Dec. 2013). Brussels, Belgium.

Food and Agriculture Organization of the United Nations (FAO) (2015) Rural and agricultural finance and investment. Rome, Italy.

Food and Agriculture Organization of the United Nations (FAO) (2016) Migration and Protracted Crises: Addressing the root causes and building resilient agricultural livelihoods. Rome, Italy.

Gálvez-Nogales E (2010) Agro-based clusters in developing countries: staying competitive in a globalized economy. Agricultural Management, Marketing and Finance Occasional Papers n. 25. FAO, Rome, Italy.

Global Partnership for Financial Inclusion (GPFI) (2015) New Trends in Agricultural Finance (Oct. 2015). Retrieved from http://bit.ly/1Pc1DUD. [Accessed 27 June 2017]. 
Holmes I, Maule S (2016) A Sustainable Finance Plan for the European Union (Oct. 2016). Third Generation Environmentalism Ltd, London, UK. Retrieved from http://bit.ly/2tI1fuH. [Accessed 2 July 2017].

International Fund for Agricultural Development (IFAD) (2016) Rural Development Report 2016 - Fostering inclusive rural transformation. Rome, Italy.

International Finance Corporation (IFC) (2012) Innovative Agricultural SME Finance Models (Nov. 2012). Washington DC, USA.

Lonsdale C (2016) Aligning blended finance with the Busan principles of development effectiveness, discussion paper (Oct. 2016). Development Initiatives, Bristol, UK.

Mori M (2008) L'innovazione finanziaria nel comparto agroalimentare [Financial innovation in the agri-food sector]. In S Dell'Atti (ed) La finanza a servizio del comparto agroalimentare - Opportunità di finanziamento e posizionamento strategico nelle filiere agroalimentari , 73-91. Naples, Italy: Edizioni Scientifiche Italiane.

Mori M (2011) Financial Innovation in Agriculture. In Agrár-és Vidékfejlesztési Szemle. University of Szeged, Hódmezővásárhely, Hungary, 6, 1 (May 2011), 11-17.

Mori M (2012) Sustainability Issues in Finance. In Rivista di Studi sulla Sostenibilità 2(1): $15-38$

Paciello M C (2015) Understanding Food Security and Agriculture Challenges in the Euro-Mediterranean Region. In MC Paciello (ed) Building Sustainable Agriculture for Food Security in the Euro-Mediterranean Area: Challenges and Policy Options. Rome, Italy: Edizioni Nuova Cultura.

Seibel HD, Kirchstein K (2011) Savings Mobilization and Meeting the Financial Needs of the Rural Poor. In Rural Finance \& Savings - UMM Workshop Report by the e-MPF Action Group University Meets Microfinance. June 17-18, 2011, University of Groningen, Groningen, The Netherlands.

Slater R, Wiggings S, Harman L, Ulrichs M, Scott L, Knowles M, Pozarny P, Calcagnini G (2016) Strengthening coherence between agriculture and social protection - Synthesis of seven country case studies. FAO, Rome.

Ushie V (2013) The Management and Use of Natural Resources and their Potential for Economic and Social Development in the Mediterranean. IAI Working Papers $\mathrm{n}$. 1329 (Oct. 2013). Istituto Affari Internazionali, Rome, Italy.

World Bank (2005) Agriculture Investment Sourcebook. Washington DC, USA.

World Bank (2011) Growth and Productivity in Agriculture and Agribusiness Evaluative Lessons from World Bank Group Experience. Washington DC, USA.

World Bank (2015) Agriculture Finance. Retrieved from http://bit.ly/2oLa8hh. [Accessed 27 June 2017].

World Commission on Environment and Development (WCED) (1987) Report of the World Commission on Environment and Development: Our Common Future. New York, NY, USA. Retrieved from http://bit.ly/1xpUwNV. [Accessed 27 June 2017]. 